\title{
Effects of DSP4 and methylphenidate on spatial memory performance in rats
}

\author{
Thomas A. Sontag • Joachim Hauser • \\ Oliver Tucha $\cdot$ Klaus W. Lange
}

Received: 25 July 2011/ Accepted: 29 September 2011/Published online: 15 October 2011

(C) The Author(s) 2011. This article is published with open access at Springerlink.com

\begin{abstract}
In this experiment, we have investigated the spatial memory performance of rats following a central noradrenaline depletion induced by three different doses of the neurotoxin $\mathrm{N}$-(2-chloroethyl)-N-ethyl-2-bromobenzylamine (DSP4) and following administration of three different doses of methylphenidate (MPH). The rats were required to find food pellets hidden on a holeboard. The sole administration of DSP4 induced only minor cognitive deficits. However, the treatment with MPH increased the reference memory error, the impulsivity and the motor activity of the DSP4-treated rats. Since the noradrenergic terminals in a DSP4-treated rat are significantly reduced, the administration of MPH has little effect on the noradrenergic system and increases dopaminergic rather than noradrenergic activity, resulting in an imbalance with relatively high dopaminergic and low noradrenergic activities. It is suggested that a reduction of noradrenaline and an increase of dopamine induce ADHD-related deficits and that the depletion of noradrenaline is not sufficient for an appropriate rat model of ADHD.
\end{abstract}

Keywords Spatial memory - DSP4 - Methylphenidate · Animal model - Attention deficit hyperactivity disorder . Rat

T. A. Sontag · J. Hauser · K. W. Lange ( $₫)$

Department of Experimental Psychology,

University of Regensburg, 93040 Regensburg, Germany

e-mail: Klaus.Lange@psychologie.uni-regensburg.de

O. Tucha

Department of Clinical and Developmental Neuropsychology,

University of Groningen, Groningen, The Netherlands

\section{Introduction}

The characteristic features of children and adolescents with attention deficit hyperactivity disorder (ADHD) are excessive motor activity, inattention and impulsiveness (e.g. Lange et al. 2010; Tucha et al. 2008, 2009). The treatment with psychostimulants such as methylphenidate is the standard pharmacological therapy of ADHD (e.g. Lange et al. 2007; Tucha et al. 2006a, b, c). Methylphenidate has been shown to increase dopaminergic and noradrenergic activity most likely by blocking noradrenaline and dopamine transporters (Heal et al. 2009). These neurotransmitters appear, therefore, to play an important role in ADHD. However, it is not fully understood how an increase in catecholaminergic activity ameliorates the symptoms of ADHD. The degeneration of the locus coeruleus (LC), which is the main source of noradrenaline in the central nervous system, has been associated with deficits in attention and selective processing of sensory stimuli (Coull 1994). An increase in noradrenaline leads to a more focused behaviour whereas a decrease in noradrenaline increases the reaction to irrelevant stimuli (Aston-Jones et al. 1997). These observations suggest that a decrease in central noradrenaline might contribute to ADHD. Since there is a similarity in symptoms between patients with ADHD and those with prefrontal lesions (Benton 1991; Heilman et al. 1991; Levin 1938; Mattes 1980) it has been postulated that the prefrontal cortex (PFC) is critically involved in ADHD. This view is underlined by the fact that abnormalities within the prefrontal cortex have been found in children with ADHD (Castellanos et al. 1996; Filipek et al. 1997; Hynd et al. 1990). The prevailing theory regarding the neurobiology of ADHD suggests an imbalance of dopamine and noradrenaline in the prefrontal cortex (Arnsten 2009, 2011; Himelstein et al. 2000). In summary, these findings suggest 
that a reduction in noradrenaline can induce prefrontal deficits which might contribute to ADHD.

In the present experiment, a depletion of central noradrenaline was induced with the neurotoxin $\mathrm{N}$-(2-chloroethyl)-N-ethyl-2-bromobenzylamine (DSP4). This neurotoxin is known to selectively destroy the terminals of the LC (Fritschy and Grzanna 1991) and to reduce the noradrenergic activity in a dose-dependent manner (Cheetham et al. 1996). We have used different doses of DSP4 to induce different imbalances between dopamine and noradrenaline and expected to find behavioural deficits related to the prefrontal cortex. In order to assess prefrontal functions such as working memory, we have used a holeboard task where rats are required to find hidden food pellets (Heim et al. 2000). Different doses of methylphenidate (MPH) were used in order to treat the expected deficits.

\section{Materials and methods}

Animals and feeding procedure

Forty-eight male Wistar rats aged about 3 months (weight approximately $230 \mathrm{~g}$ at the beginning of the experiment) were used. The animals were kept on a 12:12 h light-dark cycle (room temperature $21^{\circ} \mathrm{C}$, humidity $55 \%$ ). Water was provided ad libitum.

All experiments were performed in accordance with the national laws (German law on Protection of Animals) and the principles of laboratory animal care (NIH publication No. 86-23, revised 1985).

\section{Training, DSP4 administration and test procedure}

Prior to the administration of the neurotoxin DSP4, the rats were trained once a day on the COGITAT System until each rat had found the hidden pellets at least twice. This training period lasted approximately 3 weeks. The animals were trained in the morning and the order in which the rats were trained on the board was balanced. When the animals had reached this level, they were divided in four groups of 12 animals each. The rats in the four groups were matched according to number of pellets eaten, working memory error and reference memory error.

The animals of the control group were injected with saline (DSP4_C); the animals of the other three groups received an injection of DSP4 (Sigma-Aldrich, Schnelldorf, Germany) at a dose of $10 \mathrm{mg} / \mathrm{kg}$ (DSP4_1), $20 \mathrm{mg} / \mathrm{kg}$ (DSP4_2), or $50 \mathrm{mg} / \mathrm{kg}$ (DSP4_3). Both DSP4 and saline were administered intraperitoneally. Following the injections, the animals were not tested for 2 weeks in order to allow for a recovery of the peripheral noradrenergic system (Fritschy and Grzanna 1991). The feeding of the animals was kept constant during this period. The animals were then tested again with the same pellet pattern on the COGITAT System (10 trials per rat over 2 weeks). The rats were put on starvation rations during the week prior to testing with the COGITAT System and throughout the subsequent test periods. The rats' weight was carefully controlled and a weight reduction of more than $10-15 \%$ was avoided in order to prevent stress (Bear 1999; Deroche et al. 1995) and subsequent changes in the dopaminergic system (Pothos et al. 1995). The rats were fed $1 \mathrm{~h}$ prior to the start of testing. This procedure was chosen for two reasons: (1) rats awaiting their daily feeding after testing may not search properly during the trials; (2) feeding shortly before testing avoids the decrease in dopamine release associated with chronic food deprivation (Pothos et al. 1995).

\section{Injection of MPH}

The effects of MPH were tested using three different doses of the drug and saline as control $(2.5,5,10 \mathrm{mg} / \mathrm{kg})$. These doses have been shown to improve attentional functions as assessed with the 5-choice-serial-reaction-time task (Bizarro et al. 2004). The injections were given $10 \mathrm{~min}$ before the testing because the maximum concentration in the brain can be measured within the first 20 min after administration (Huff and Davies 2002). Each rat was tested with saline and the three MPH doses. Saline and each MPH dose were injected over five consecutive days. In order to avoid carry-over effects, the order in which the rats were injected was balanced using Latin squares. A wash-out period of 3 days was used (Yang et al. 2003).

\section{COGITAT Hole Board}

The learning behaviour of the rats was tested with the COGITAT Hole Board System (Cogitron GmbH, Göttingen, Germany). This system consists of a board with 25 holes (Fig. 1). Each hole of the board is closed at its lower end by an adjustable feeding plate with a depression for a food pellet. Feeding plate and food pellets are of the same colour. The ground below the feeding plate is covered with the same pellets as those used in the cylindrical tubes, in order to prevent the animals from finding the pattern of the pellet distribution by using olfactory stimuli. Each hole is fitted with infra-red light beams at different levels of the hole to measure activity. Finally, there is an infra-red beam at the feeding plate measuring the collection of a food pellet. A more detailed description of the COGITAT Hole Board System can be found elsewhere (Heim et al. 2000).

In the present experiment, eight of the 25 holes were baited (Fig. 1). A search trial was automatically finished when a rat had found all the hidden pellets or after a fixed period of time (60 s). 


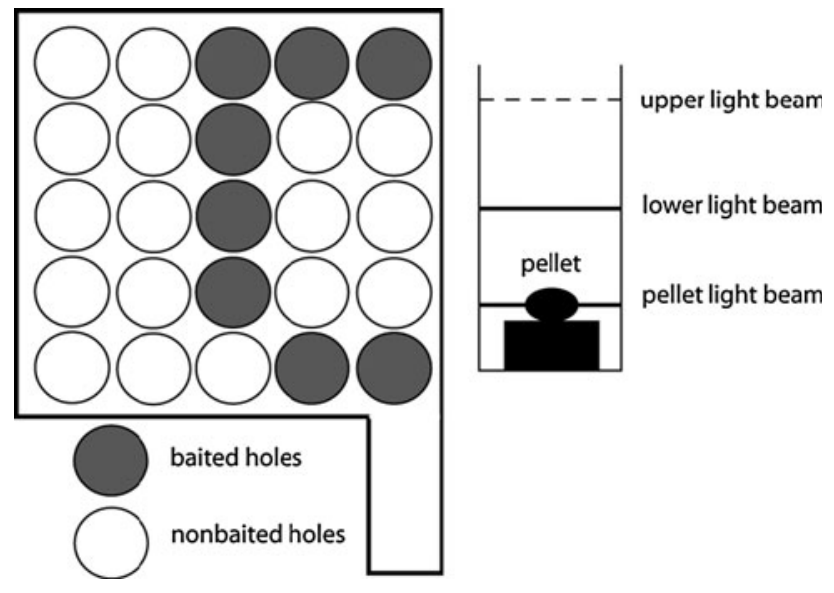

Fig. 1 Schematic drawing of the COGITAT system

In each single trial, the following parameters were measured: (1) working memory error (i.e. the percentage of inspections to previously baited holes in a single trial in relation to the total number of holes inspected); (2) reference memory error (i.e. the percentage of inspections to non-baited holes in relation to the total number of holes inspected); (3) pellets eaten (the number of pellets eaten); (4) inspections (i.e. the number of interruptions of the upper light beam only).

In addition, all trials were recorded with a video system. This data was digitalised and analysed using the video tracking system ETHOVISION 3.0 (Noldus, Wageningen, The Netherlands). The parameter measured was the route covered, i.e. the distance travelled by the rats (per trial, in $\mathrm{cm}$ ).

\section{Statistics}

Statistical analyses were performed using the non-parametric Wilcoxon-test, an alpha level of 0.05 was applied. The analyses were performed using the Statistical Package for Social Sciences 13.0 (SPSS) for Windows.

\section{Results}

In the following, the calculated values are given as means \pm standard error of the means.

Pellets eaten (Fig. 2)

\section{Comparison between the DSP4 groups after saline injection}

The DSP4 groups differed in the saline condition, whereas the DSP4_C group found significantly more pellets

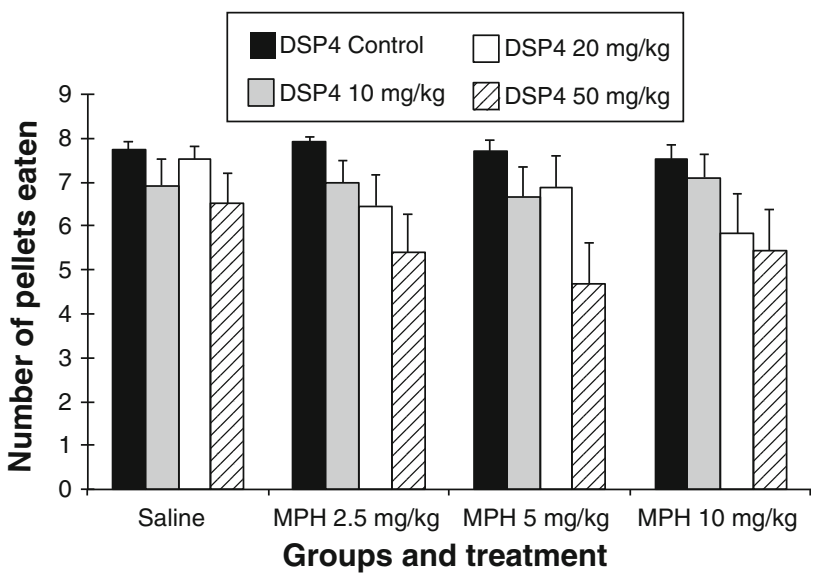

Fig. 2 Number of pellets eaten (error bars indicate SEM)

compared to the DSP4_1 (7.74 \pm 0.18 vs. $6.93 \pm 0.59$; $P \leq 0.01)$ and the DSP4_3 (7.74 \pm 0.18 vs. $6.52 \pm 0.69$; $P \leq 0.01)$. The DSP4_2 group found more pellets than the DSP4_1 group $(7.52 \pm 0.31$ vs. $6.93 \pm 0.59 ; P \leq 0.05)$ and the DSP4_3 group $(7.52 \pm 0.31$ vs. $6.52 \pm 0.69$; $P \leq 0.05)$.

\section{Treatment with MPH in the DSP4_C group}

The treatment of the rats in the DSP4_C group with MPH at a dose of $2.5 \mathrm{mg} / \mathrm{kg}$ induced a small but significant increase in pellets found in comparison with the saline injection (saline vs. MPH $2.5 \mathrm{mg}: 7.74 \pm 0.18$ vs. $7.93 \pm$ $0.09 ; P \leq 0.05$ ). Treating this group with $10 \mathrm{mg} / \mathrm{kg}$ of MPH decreased the number of pellets eaten compared to the treatment with $2.5 \mathrm{mg}$ MPH (MPH $2.5 \mathrm{mg}$ vs. MPH $10 \mathrm{mg}$ : $7.93 \pm 0.09$ vs. $7.53 \pm 0.33 ; P \leq 0.05)$.

Treatment with MPH in the DSP4_1 group (10 $\mathrm{mg} / \mathrm{kg}$ DSP4)

The treatment of the DSP4_1 group with MPH had no statistically significant effects on the number of pellets eaten in comparison with the saline injection.

Treatment with $M P H$ in the DSP4_2 group (20 $\mathrm{mg} / \mathrm{kg}$ DSP4)

The treatment of the DSP4_2 group with the high dose of MPH $(10 \mathrm{mg} / \mathrm{kg})$ resulted in a significant decrease in the number of pellets eaten in comparison with the saline injection (saline vs. MPH $10 \mathrm{mg}: 7.52 \pm 0.31$ vs. $5.82 \pm$ $0.90 ; P \leq 0.01)$. The treatment with $2.5 \mathrm{mg} / \mathrm{kg}$ of MPH also induced a reduction in the number of pellets eaten (saline vs. MPH $2.5 \mathrm{mg}$ : $7.52 \pm 0.31$ vs. $6.46 \pm 0.70$; $P \leq 0.05)$. 


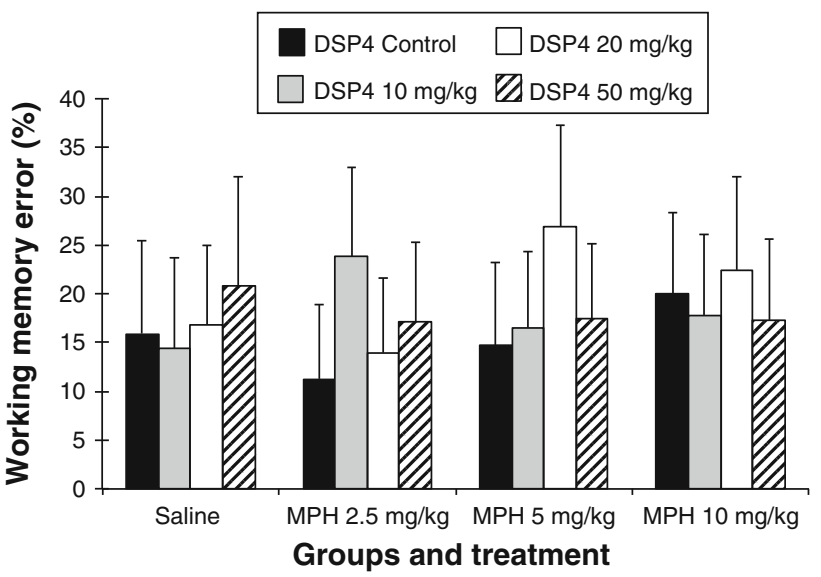

Fig. 3 Working memory error (error bars indicate SEM)

Treatment with MPH in the DSP4_3 group (50 $\mathrm{mg} / \mathrm{kg} \mathrm{DSP} 4)$

The treatment of the DSP_3 group with $5 \mathrm{mg} / \mathrm{kg}$ of MPH induced a significant decrease in the number of pellets eaten in comparison with the saline injection (saline vs. MPH $5 \mathrm{mg}$ : $6.52 \pm 0.69$ vs. $4.67 \pm 0.95 ; P \leq 0.01)$. The low dose of MPH also reduced this number (saline vs. MPH $2.5 \mathrm{mg}$ : $6.52 \pm 0.69$ vs. $5.41 \pm 0.86 ; P \leq 0.05$ ). The high dose of MPH had no statistically significant effect on the number of pellets eaten.

Working memory error (Fig. 3)

\section{Comparison between the DSP4 groups after saline} injection

There were no significant differences between the groups. However, the highest dose of DSP4 induced an increase in the working memory error.

\section{Treatment with MPH in the DSP4_C group}

No significant differences between the three doses of MPH and saline injection were found.

\section{Treatment with MPH in the DSP4_1 group \\ (10 mg/kg DSP4)}

No significant differences between the three doses of MPH and saline injection were found.

Treatment with MPH in the DSP4_2 group (20 $\mathrm{mg} / \mathrm{kg}$ DSP4)

A significant difference was found between the doses of 2.5 and $5 \mathrm{mg} / \mathrm{kg}$ of MPH (MPH $2.5 \mathrm{mg}$ vs. MPH $5 \mathrm{mg}$ :

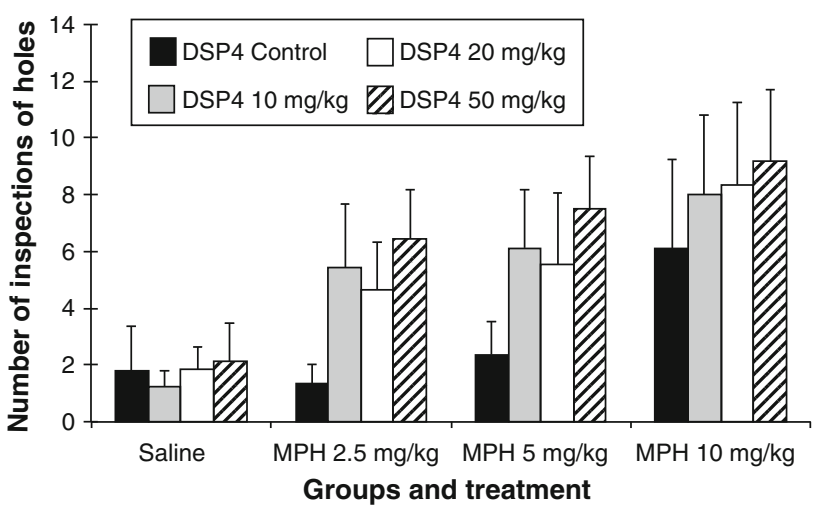

Fig. 4 Number of inspections of holes (error bars indicate SEM)

$13.95 \pm 7$. vs. $26.81 \pm 10.43 ; P \leq 0.05$ ). No other significant differences were found.

Treatment with MPH in the DSP4_3 group (50 $\mathrm{mg} / \mathrm{kg}$ DSP4)

No significant differences between the three doses of MPH and saline injection were found.

Inspections (Fig. 4)

Comparison between the DSP4 groups after saline injection

There are no significant differences.

\section{Treatment with MPH in the DSP4_C group}

MPH at a dose of 2.5 or $5 \mathrm{mg} / \mathrm{kg}$ had no significant effect on the number of inspections compared to saline. However, the dose of $10 \mathrm{mg} / \mathrm{kg}$ significantly increased the inspection rate compared to saline (saline vs. MPH $10 \mathrm{mg}: 1.81 \pm$ 1.56 vs. $6.10 \pm 3.16 ; P \leq 0.01)$.

Treatment with MPH in the DSP4_1 group (10 $\mathrm{mg} / \mathrm{kg} \mathrm{DSP4)}$

The treatment with MPH increased the number of inspections in this group in a dose-dependent manner. In comparison to the saline injection, the increase in inspections was significant for the MPH doses of $2.5 \mathrm{mg} / \mathrm{kg}$ (saline vs. MPH $2.5 \mathrm{mg}: 1.25 \pm 0.54$ vs. $5.45 \pm 2.20 ; P \leq 0.01$ ), $5 \mathrm{mg} / \mathrm{kg}$ (saline vs. MPH $5 \mathrm{mg}$ : $1.25 \pm 0.54$ vs. $6.13 \pm 2.02 ; P \leq 0.01)$ and $10 \mathrm{mg} / \mathrm{kg}$ (saline vs. MPH $10 \mathrm{mg}$ : $1.25 \pm 0.54$ vs. $8.02 \pm 2.81$; $P \leq 0.01)$. 
Treatment with MPH in the DSP4_2 group

(20 $\mathrm{mg} / \mathrm{kg} \mathrm{DSP4)}$

The treatment with all three doses of MPH significantly increased the number of inspections compared to the saline injection: with $2.5 \mathrm{mg} / \mathrm{kg}$ (saline vs. MPH $2.5 \mathrm{mg}$ : $1.83 \pm$ 0.81 vs. $4.66 \pm 1.68 ; P \leq 0.05$ ), with $5 \mathrm{mg} / \mathrm{kg}$ (saline vs. MPH $5 \mathrm{mg}: 1.83 \pm 0.81$ vs. $5.54 \pm 2.54 ; P \leq 0.05)$ and with $10 \mathrm{mg} / \mathrm{kg}$ (saline vs. MPH $10 \mathrm{mg}$ : $1.83 \pm 0.81$ vs. $8.36 \pm 2.54 ; P \leq 0.05)$.

Treatment with MPH in the DSP4_3 group (50 $\mathrm{mg} / \mathrm{kg} \mathrm{DSP4)}$

The treatment with all three doses of MPH significantly increased the number of inspections compared to the saline injection: (saline vs. MPH $2.5 \mathrm{mg}: 2.13 \pm 1.36$ vs. $6.47 \pm$ 1.73; $P \leq 0.01$ ), (saline vs. MPH $5 \mathrm{mg}: 2.13 \pm 1.36$ vs. $7.52 \pm 1.82 ; \quad P \leq 0.01$ ) and (saline vs. MPH $10 \mathrm{mg}$ : $2.13 \pm 1.36$ vs. $9.17 \pm 2.52 ; P \leq 0.01)$.

Reference memory error (Fig. 5)

Comparison between the DSP4 groups after saline injection

The treatment with saline did not have any effect on this parameter in the DSP4 treated groups.

\section{Treatment with MPH in the DSP4_C group}

The treatment with $10 \mathrm{mg} / \mathrm{kg}$ of MPH induced a significant increase in the reference memory error compared to saline injection (saline vs. MPH $10 \mathrm{mg}$ : $15.98 \pm 9.55$ vs. $38.42 \pm 11.43 ; P \leq 0.01)$ and to the dose of $2.5 \mathrm{mg} / \mathrm{kg}$ of MPH (MPH $2.5 \mathrm{mg}$ vs. MPH $10 \mathrm{mg}: 22.85 \pm 10.80$ vs. $38.42 \pm 11.43 ; P \leq 0.05)$.

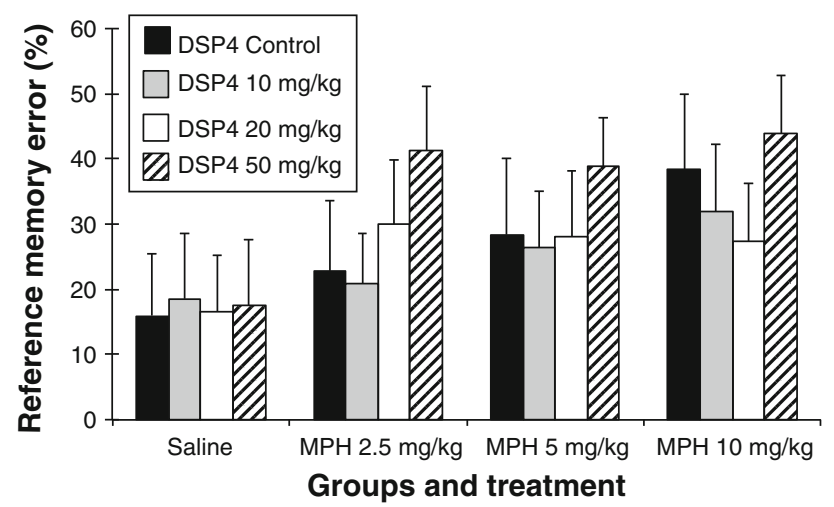

Fig. 5 Reference memory error (error bars indicate SEM)
Treatment with MPH in the DSP4_1 group (10 $\mathrm{mg} / \mathrm{kg} \mathrm{DSP4)}$

The treatment with $10 \mathrm{mg} / \mathrm{kg}$ of MPH induced a significant increase in the reference memory error compared to saline injection (saline vs. MPH $10 \mathrm{mg}$ : $18.56 \pm 10.08$ vs. $31.83 \pm 10.36 ; P \leq 0.05)$.

Treatment with MPH in the DSP4_2 group (20 $\mathrm{mg} / \mathrm{kg} \mathrm{DSP4)}$

The treatment of the DSP4_2 group with MPH at doses of 2.5 and $10 \mathrm{mg} / \mathrm{kg}$ increased the reference memory error compared to the saline injection (saline vs. MPH $2.5 \mathrm{mg}$ : $16.62 \pm 8.55$ vs. $29.98 \pm 9.80 ; P \leq 0.05$ ), (saline vs. MPH $10 \mathrm{mg}$ : $16.62 \pm 8.55$ vs. $27.42 \pm 8.82 ; P \leq 0.05)$.

Treatment with MPH in the DSP4_3 group (50 $\mathrm{mg} / \mathrm{kg} \mathrm{DSP4)}$

The treatment with all three doses of MPH significantly increased the reference memory error compared to the saline injection (saline vs. MPH $2.5 \mathrm{mg}$ : $17.45 \pm 10.07$ vs. $41.37 \pm 9.65 ; P \leq 0.01$ ), (saline vs. MPH $5 \mathrm{mg}$ : $17.45 \pm$ 10.07 vs. $38.83 \pm 7.44 ; \mathrm{p} \leq 0.01$ ), (saline vs. MPH $10 \mathrm{mg}$ : $17.45 \pm 10.07$ vs. $43.97 \pm 8.78 ; P \leq 0.01)$.

Route covered (Fig. 6)

Comparison between the DSP4 groups after saline injection

There was no significant difference between the groups.

\section{Treatment with MPH in the DSP4_C group}

The high dose of MPH induced an increase in the route covered (saline vs. MPH $10 \mathrm{mg}$ : $193.75 \pm 55.93$ vs. $320.84 \pm 92.62 ; P \leq 0.01)$.

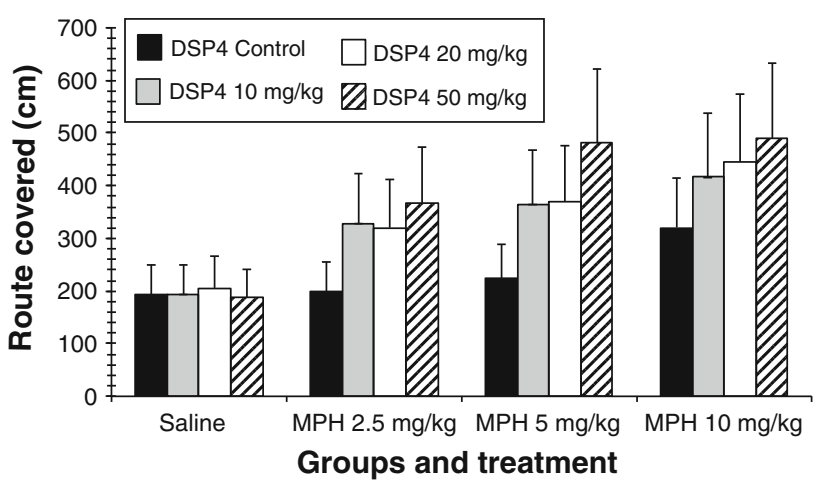

Fig. 6 Route covered (error bars indicate SEM) 
Treatment with MPH in the DSP4_1 group

(10 $\mathrm{mg} / \mathrm{kg}$ DSP4)

All MPH doses increased the route covered in comparison with the saline injection (saline vs. MPH $2.5 \mathrm{mg}$ : $193.50 \pm$ 55.86 vs. $328.57 \pm 94.85 ; P \leq 0.01$ ), (saline vs. $\mathrm{MPH}$ $5 \mathrm{mg}$ : $193.50 \pm 55.86$ vs. $364.05 \pm 105.09 ; P \leq 0.01)$, (saline vs. MPH $10 \mathrm{mg}$ : $193.50 \pm 55.86$ vs. $416.56 \pm$ 120.25; $P \leq 0.01)$.

\section{Treatment with MPH in the DSP4_2 group} (20 $\mathrm{mg} / \mathrm{kg}$ DSP4)

All MPH doses increased the route covered in comparison with the saline injection (saline vs. MPH $2.5 \mathrm{mg}$ : $205.87 \pm$ 59.43 vs. $320.41 \pm 92.50 ; P \leq 0.01$ ), (saline vs. $\mathrm{MPH}$ $5 \mathrm{mg}: 205.87 \pm 59.43$ vs. $368.54 \pm 106.39 ; P \leq 0.05$ ), (saline vs. MPH $10 \mathrm{mg}: 205.87 \pm 59.43$ vs. $445.87 \pm$ 128.71; $P \leq 0.01)$.

\section{Treatment with $M P H$ in the DSP4_3 group} (50 $\mathrm{mg} / \mathrm{kg} \mathrm{DSP} 4)$

All MPH doses increased the route covered in comparison with the saline injection (saline vs. MPH $2.5 \mathrm{mg}: 187.17 \pm$ 54.03 vs. $367.36 \pm 106.05 ; P \leq 0.01$ ), (saline vs. $\mathrm{MPH}$ $5 \mathrm{mg}: 187.17 \pm 54.03$ vs. $482.40 \pm 139.26 ; P \leq 0.01)$, (saline vs. $\mathrm{MPH} 10 \mathrm{mg}: 187.17 \pm 54.03$ vs. $490.70 \pm$ 141.65; $P \leq 0.01)$.

\section{Discussion}

The present experiment was performed in order to investigate the effects of noradrenaline depletion on cognition in rats and the administration of MPH. Given the role of the LC in the regulation of attention processes, we expected to find impaired cognition due to the administration of DSP4.

The animal groups treated with three different doses of DSP4 differed significantly in the number of pellets eaten. The rats treated with the low and the high doses of DSP4 ate the lowest number of pellets compared to the saline group (Fig. 2). Similar differences were also observed in our previous experiment (Sontag et al. 2008) indicating cognitive difficulties in the DSP4-treated rats. The LC neurons project, among others, to the prefrontal cortex and show two distinct firing modes, i.e. (1) tonic firing which is associated with arousal, sensory information processing, attention, working memory and motor processes (Arnsten and Dudley 2005; Aston-Jones et al. 1994; Devilbiss and Waterhouse 2004; Foote et al. 1980, 1983) and (2) phasic discharge which is associated with alerting and orienting reactions, sustained attention and decision-making (Aston-Jones et al. 1994; Clayton et al. 2004). We therefore expected to find deficits in working memory. With increasing doses of DSP4 a non-significant increase in working memory error was found (Fig. 3). No increase was found for the reference memory error (Fig. 5). This suggests that DSP4 induces deficits in working memory rather than in reference memory.

The administration of MPH induced only minor effects. There was a small but significant increase in the number of pellets eaten following the administration of $2.5 \mathrm{mg} / \mathrm{kg}$ MPH. The working memory error decreased, though not significantly, following treatment with $2.5 \mathrm{mg} / \mathrm{kg}$ of MPH, indicating an improvement in cognition. However, with increasing doses both the reference and the working memory error increased, suggesting a decline in cognitive functions (Figs. 3, 5) An impairment of working memory with increasing doses of MPH was also reported by Devilbiss and Berridge (2008) who showed that MPH at a dose of $2.0 \mathrm{mg} / \mathrm{kg}$ induces severe deficits in working memory whereas a dose below $2.0 \mathrm{mg} / \mathrm{kg}$ enhances working memory in naïve rats. It was also reported that the administration of $2.5 \mathrm{mg} / \mathrm{kg}$ MPH induced a significant increase in motor activity (Gaytan et al. 1997) and the use of small MPH doses was suggested by Arnsten and Dudley (2005) in order to avoid the stimulating effects on motor activity. However, the rats in the present study did not walk longer distances after 2.5 or $5 \mathrm{mg} / \mathrm{kg}$ of MPH (Fig. 6). Only the high dose of MPH increased the distances walked by the rats. The effect on working memory was minor compared to the data presented by Devilbiss and Berridge (2008). Both Devilbiss and Berridge (2008) and Gaytan et al. (1997) used SpragueDawley rats whereas we used Wistar rats. The present results may therefore suggest a reduced sensitivity to the effects of MPH in Wistar rats. Furthermore, it can be excluded that the alterations in cognitive functions found in the DSP4-C group after the injection of 2.5 or $5 \mathrm{mg} / \mathrm{kg}$ MPH are related to an increase in motor activity.

The pre-treatment with DSP4 appears to potentiate the effects of MPH. The treatment of the DSP4_3 group with $2.5 \mathrm{mg} / \mathrm{kg}$ MPH significantly increased the reference memory error which did not further increase with higher doses of MPH. This finding suggests a ceiling effect (Fig. 5). The increase in reference memory error was associated with a decrease in the number of pellets eaten (Fig. 2). These findings indicate a deficit in spatial memory induced by MPH. This is underlined by the fact that the rats travelled significantly longer distances during the testing (Fig. 6). The dose of $2.5 \mathrm{mg} / \mathrm{kg}$ MPH had no such effects on the DSP4-C group, on the contrary, this dose slightly increased the cognition in the rats. An increase in the reference memory error, a decrease in the pellets eaten, and an increase in the distance travelled were, though less pronounced, also observed in the DSP4_2 group (Figs. 2, 5, 6). 
By contrast, the DSP4_1 group showed only a significant increase in the reference memory error after the high dose of MPH (Fig. 5). These findings suggest that the pre-treatment with different doses of DSP4 induced different sensitivities to MPH, leading to deficits in spatial reference memory.

It was expected that MPH would reduce working memory deficits in DSP4-treated rats. Since MPH increases noradrenaline release, it was also expected that this effect would be more pronounced in the groups treated with the low doses of DSP4 because more noradrenergic LC terminals would survive this treatment (Cheetham et al. 1996). However, no significant effects of MPH on working memory compared to saline were found in any of the DSP4-treated groups. The effects of MPH and DSP4 on reference memory and the lack of effects on working memory suggest that the MPH and DSP4 might have affected brain structures outside the prefrontal cortex, most likely the hippocampus.

Both prefrontal cortex and hippocampus receive innervations from the LC (Foote et al. 1983). The administration of DSP4 may therefore have depleted noradrenaline in both brain regions. For the hippocampus, Chrobak et al. (1985) reported a significant decrease of noradrenaline but no effect on dopamine following the administration of DSP4 in rats. This study also showed that the administration of DSP4 did not affect spatial memory. Another study has shown that a decrease in dopamine disturbs spatial learning (Gasbarri et al. 1996). MPH increases both dopamine and noradrenaline release. In DSP4-treated rats, however, noradrenaline release is markedly reduced since DSP4 destroys the noradrenergic terminals. One would therefore expect that MPH increased dopamine release in the hippocampus. This reasoning is in contrast to the finding that a decrease in hippocampal dopamine disturbs spatial learning (Gasbarri et al. 1996).

Another possibility is that the increase in reference memory error in DSP4-treated rats after MPH administration is related to an increase in motor activity. We found no stimulation of motor behaviour in saline-treated rats but in all DSP4 pre-treated rats MPH induced a significant increase in motor activity (Fig. 6) Furthermore, MPH also increased the number of inspections, indicating an increase in impulsive behaviour (Fig. 4). This suggests that a reduction of noradrenaline in combination with an increase in dopamine induce motor hyperactivity and impulsivity, two core symptoms of ADHD.

In summary, central noradrenaline depletion following DSP4 administration induced cognitive deficits without affecting reference memory. The treatment with MPH affected reference memory rather than working memory. In addition, there were indications that MPH also increased impulsivity and motor activity of the DSP4-treated rats, which are two core symptoms of ADHD. Since the noradrenergic terminals in a DSP4-treated rat are significantly reduced, the administration of MPH increases dopaminergic activity rather than noradrenergic activity. These results therefore suggest that a reduction of noradrenaline and an increase of dopamine may induce ADHD-related deficits. The sole depletion of noradrenaline is therefore not sufficient for an appropriate rat model of ADHD (see Sontag et al. 2010).

Open Access This article is distributed under the terms of the Creative Commons Attribution Noncommercial License which permits any noncommercial use, distribution, and reproduction in any medium, provided the original author(s) and source are credited.

\section{References}

Arnsten AF (2009) Toward a new understanding of attention-deficit hyperactivity disorder pathophysiology: an important role for prefrontal cortex dysfunction. CNS Drugs 23(Suppl 1):33-41

Arnsten AF (2011) Catecholamine influences on dorsolateral prefrontal cortical networks. Biol Psychiatry 69:89-99

Arnsten AF, Dudley AG (2005) Methylphenidate improves prefrontal cortical cognitive function through alpha2 adrenoceptor and dopamine D1 receptor actions: relevance to therapeutic effects in attention deficit hyperactivity disorder. Behav Brain Funct 1:2

Aston-Jones G, Rajkowski J, Kubiak P, Alexinsky T (1994) Locus coeruleus neurons in monkey are selectively activated by attended cues in a vigilance task. J Neurosci 14:4467-4480

Aston-Jones G, Rajkowski J, Kubiak P (1997) Conditioned responses of monkey locus coeruleus neurons anticipate acquisition of discriminative behavior in a vigilance task. Neuroscience 80:697-715

Bear MF (1999) Homosynaptic long-term depression: a mechanism for memory? Proc Natl Acad Sci USA 96:9457-9458

Benton A (1991) Prefrontal injury and behavior in children. Dev Neuropsychol 7:275-282

Bizarro L, Patel S, Murtagh C, Stolerman IP (2004) Differential effects of psychomotor stimulants on attentional performance in rats: nicotine, amphetamine, caffeine and methylphenidate. Behav Pharmacol 15:195-206

Castellanos FX, Giedd JN, Marsh WL, Hamburger SD, Vaituzis AC, Dickstein DP, Sarfatti SE, Vauss YC, Snell JW, Lange N, Kaysen D, Krain AL, Ritchie GF, Rajapakse JC, Rapoport JL (1996) Quantitative brain magnetic resonance imaging in attention-deficit hyperactivity disorder. Arch Gen Psychiatry 53:607-616

Cheetham SC, Viggers JA, Butler SA, Prow MR, Heal DJ (1996) $[3 \mathrm{H}]$ nisoxetine $-\mathrm{a}$ radioligand for noradrenaline reuptake sites: correlation with inhibition of $[3 \mathrm{H}]$ noradrenaline uptake and effect of DSP-4 lesioning and antidepressant treatments. Neuropharmacology 35:63-70

Chrobak JJ, DeHaven DL, Walsh TJ (1985) Depletion of brain norepinephrine with DSP-4 does not alter acquisition or performance of a radial-arm maze task. Behav Neural Biol 44:144-150

Clayton EC, Rajkowski J, Cohen JD, Aston-Jones G (2004) Phasic activation of monkey locus ceruleus neurons by simple decisions in a forced-choice task. J Neurosci 24:9914-9920

Coull JT (1994) Pharmacological manipulations of the alpha 2-noradrenergic system. Effects on cognition. Drugs Aging 5:116-126

Deroche V, Marinelli M, Maccari S, Le Moal M, Simon H, Piazza PV (1995) Stress-induced sensitization and glucocorticoids. 
I. Sensitization of dopamine-dependent locomotor effects of amphetamine and morphine depends on stress-induced corticosterone secretion. J Neurosci 15:7181-7188

Devilbiss DM, Berridge CW (2008) Cognition-enhancing doses of methylphenidate preferentially increase prefrontal cortex neuronal responsiveness. Biol Psychiatry 64:626-635

Devilbiss DM, Waterhouse BD (2004) The effects of tonic locus ceruleus output on sensory-evoked responses of ventral posterior medial thalamic and barrel field cortical neurons in the awake rat. J Neurosci 24:10773-10785

Filipek PA, Semrud-Clikeman M, Steingard RJ, Renshaw PF, Kennedy DN, Biederman J (1997) Volumetric MRI analysis comparing subjects having attention-deficit hyperactivity disorder with normal controls. Neurology 48:589-601

Foote SL, Aston-Jones G, Bloom FE (1980) Impulse activity of locus coeruleus neurons in awake rats and monkeys is a function of sensory stimulation and arousal. Proc Natl Acad Sci USA 77:3033-3037

Foote SL, Bloom FE, Aston-Jones G (1983) Nucleus locus ceruleus: new evidence of anatomical and physiological specificity. Physiol Rev 63:844-914

Fritschy JM, Grzanna R (1991) Experimentally-induced neuron loss in the locus coeruleus of adult rats. Exp Neurol 111:123-127

Gasbarri A, Sulli A, Innocenzi R, Pacitti C, Brioni JD (1996) Spatial memory impairment induced by lesion of the mesohippocampal dopaminergic system in the rat. Neuroscience 74:1037-1044

Gaytan O, Ghelani D, Martin S, Swann A, Dafny N (1997) Methylphenidate: diurnal effects on locomotor and stereotypic behavior in the rat. Brain Res 777:1-12

Heal DJ, Cheetham SC, Smith SL (2009) The neuropharmacology of ADHD drugs in vivo: insights on efficacy and safety. Neuropharmacology 57:608-618

Heilman KM, Voeller KK, Nadeau SE (1991) A possible pathophysiologic substrate of attention deficit hyperactivity disorder. J Child Neurol 6(Suppl):76-81

Heim C, Pardowitz I, Sieklucka M, Kolasiewicz W, Sontag T, Sontag KH (2000) The analysis system COGITAT for the study of cognitive deficiencies in rodents. Behav Res Methods Instrum Comput 32:140-156

Himelstein J, Newcorn JH, Halperin JM (2000) The neurobiology of attention-deficit hyperactivity disorder. Front Biosci 5:461-478

Huff JK, Davies MI (2002) Microdialysis monitoring of methylphenidate in blood and brain correlated with changes in dopamine and rat activity. J Pharm Biomed Anal 29:767-777

Hynd GW, Semrud-Clikeman M, Lorys AR, Novey ES, Eliopulos D (1990) Brain morphology in developmental dyslexia and attention deficit disorder/hyperactivity. Arch Neurol 47:919-926
Lange KW, Tucha L, Walitza S, Gerlach M, Linder M, Tucha O (2007) Interaction of attention and graphomotor functions in children with attention deficit hyperactivity disorder. J Neural Transm Suppl 72:249-259

Lange KW, Reichl S, Lange KM, Tucha L, Tucha O (2010) The history of attention deficit hyperactivity disorder. Atten Defic Hyperact Disord 2:241-255

Levin PM (1938) Restlessness in children. Arch Neurol Psychiatry 39:764-770

Mattes JA (1980) The role of frontal lobe dysfunction in childhood hyperkinesis. Compr Psychiatry 21:358-369

Pothos EN, Hernandez L, Hoebel BG (1995) Chronic food deprivation decreases extracellular dopamine in the nucleus accumbens: implications for a possible neurochemical link between weight loss and drug abuse. Obes Res 3(Suppl 4):525-529

Sontag TA, Hauser J, Kaunzinger I, Gerlach M, Tucha O, Lange KW (2008) Effects of the noradrenergic neurotoxin DSP4 on spatial memory in the rat. J Neural Transm 115:299-303

Sontag TA, Tucha O, Walitza S, Lange KW (2010) Animal models of attention deficit/hyperactivity disorder (ADHD): a critical review. Atten Defic Hyperact Disord 2:1-20

Tucha O, Mecklinger L, Laufkötter R, Klein HE, Walitza S, Lange KW (2006a) Methylphenidate-induced improvements of various measures of attention in adults with attention deficit hyperactivity disorder. J Neural Transm 113:1575-1592

Tucha O, Walitza S, Mecklinger L, Sontag TA, Kübber S, Linder M, Lange KW (2006b) Attentional functioning in children with ADHD-predominantly hyperactive-impulsive type and children with ADHD-combined type. J Neural Transm 113:1943-1953

Tucha O, Prell S, Mecklinger L, Bormann-Kischkel C, Kübber S, Linder M, Walitza S, Lange KW (2006c) Effects of methylphenidate on multiple components of attention in children with attention deficit hyperactivity disorder. Psychopharmacology (Berl) 185:315-326

Tucha L, Tucha O, Laufkötter R, Walitza S, Klein HE, Lange KW (2008) Neuropsychological assessment of attention in adults with different subtypes of attention-deficit/hyperactivity disorder. J Neural Transm 115:269-278

Tucha L, Tucha O, Walitza S, Sontag TA, Laufkötter R, Linder M, Lange KW (2009) Vigilance and sustained attention in children and adults with ADHD. J Atten Disord 12:410-421

Yang PB, Amini B, Swann AC, Dafny N (2003) Strain differences in the behavioral responses of male rats to chronically administered methylphenidate. Brain Res 971:139-152 